\title{
Evolution of Air Transport Networks under Different Airline Business Models: The Case of Three Chinese Airlines
}

\author{
Weiwei Wu ${ }^{1}$, Haoyu Zhang ${ }^{2}$,Siqi Lin $^{3}$, Frank Witlox ${ }^{4}$ \\ ${ }^{1}$ Department of Civil Aviation, Nanjing University of Aeronautics and Astronautics, Nanjing, China \\ ${ }^{2}$ Department of Civil Aviation, Nanjing University of Aeronautics and Astronautics, Nanjing, China \\ ${ }^{3}$ Department of Civil Aviation, Nanjing University of Aeronautics and Astronautics, Nanjing, China \\ ${ }^{4}$ Department of Geography, Ghent University, Ghent, Belgium
}

\begin{abstract}
This study was conducted to compare the evolution process of air transport networks (ATNs) under different airline business models, and empirically analyzed the causes of evolution differences combining with airline market behaviors. Three representative Chinese airlines (China Southern Airlines, Spring Airlines, and Lucky Air) that belong to three business models (full-service, low-cost, and regional) were examined. Based on mathematical statistics and complex network theory, from spatial pattern, topological feature and central city, the result showed that the airlines have their own unique evolution characteristics of ATNs driven by different business models. China southern airlines as state-owned full-service network carrier, its ATN is easily affected by national policy. Spring Airlines has more flexible and diverse choice in choosing target markets and the ATN had a transformation from a mono-centric divergence network to a two-centric regional one. Lucky Air as a regional feeder carrier, whether navigable airports or navigable routes increasingly concentrated within the southwest of China. This information is important for government to improve the national ATN by developing targeted airlines.
\end{abstract}

\section{Introduction}

Since the year 1986, the Civil Aviation Administration of China (CAAC) has gradually started to implement various reform measures including: transforming airlines from controlled in a tightly regulated system into profit-driven business entities; and allowing local governments to operate their own airlines and encouraging competition. In 2002, the CAAC advocated airline consolidation to create more cost-efficient airlines that could achieve economies of scale, and all state-owned were regrouped into the "Big Three" airlines that are full-service network carriers (FSNCs): Air China, China Southern, and China Eastern [1]. Then, in 2005, the CAAC opened its civil aviation sector to private investors, and the number of private airlines including low-cost carriers (LCCs) has grown rapidly. More recently, recognizing the driving effect of regional feeder airlines on social and economic development, local governments constantly increase investment and support for feeder aviation industry.

Thus, in China, we currently observe - as a result of the liberalization and deregulation - three business model airline that offer scheduled flights: (i) full-service network carriers (offering a variety of services and network linkages achieving accessibility across the country and even international areas, primarily operated by the state or local government); (ii) low-cost carriers (offering a limited number of services on specific segments across non-traditional hubs of the network at low prices, mainly on a point-to-point basis); (iii) regional feeder airline (offering higher frequency service on short-and mediumhaul routes within a given marketing area from widely scattered points to a few terminal points).

Review of literatures on the airline business model suggest that the business model is a fundamental building block to any airlines as it provides gist to deliver strategic market behaviors [2]. That is, airlines with different business models will show different market behaviors in their network design, which will lead to different evolution of air transport network (ATN).

Therefore, we respectively select three representative Chinese airlines (China Southern Airlines, Spring Airlines and Lucky Air) from three airline business models as research object to explore the evolution of different ATNs. It is interesting because of not only the Spring Airline and Lucky Air belonging to novel business models developed rather fast after the deregulation policy, but also the three airlines have their own unique network structures.

\section{Ptheoreticaling Frame}

In the early 20th century, with the popularity and wide application of the complex network theory [3], comprehensive analysis of the characteristics of ATNs under different spatial and temporal dimensions has drawn much attention.

Some studies primarily focus on the static state of 
ATNs within one year under different spatial levels: the worldwide level [4-5]; the regional level for Europe [6-7]; and the national level e.g., India [8], Italy [9], US [10] and China [11-13]. Other studies are interested in the historical evolution of ATNs [14-17]. Findings from their research can be summarized as follows: First, almost all types of ATNs examined were small-world networks with scalefree properties. Second, the process of ATN evolution generally can be divided into several stages. Third, some ATNs are gradually forming a spatial hierarchical structure and the major driving forces of network evolution is an aging effect and preferential attachment.

The ATN at the national level and even at the worldwide level are built by airlines with different enterprise behaviors that strongly influence the configuration and evolution of ATN. So far, there have several studies on the ATN evolution focused on one airline or airlines with same business model. Jiao and Wang found that the network of Hainan Airlines expanded significantly to the north of China, and flights were concentrated in a few navigable cities and routes, but the concentration had a downward trend[18]. Jiang et al. found Spring Airlines actively launched air routes between tourist cities with non-class I airports, its network has been transformed from a star structure into a complex one with multi-hubs during 2005-2013[19]. Halpern et al. investigated how LCC developments have affected the traffic and financial performance of UK airports from 2002 to 2014[20]. Dobruszkes observed the fast development of LCCs in Europe, and found that LCCs give fresh impetus to point-to-point routes by drawing new networks complementing those of FSNCs[21]. John and Bowen assessed the evolution of FedEx's and UPS's ATNs based on graph theory measures, including their spatial extent, hub locations, and network structure [22].

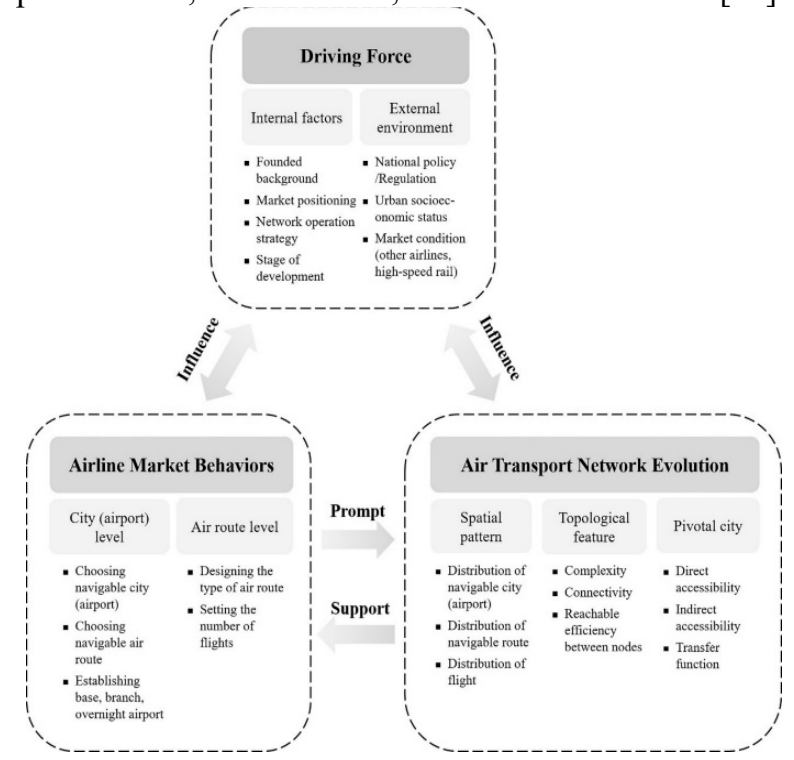

Fig1. The theoretical framework for the evolution of the ATN of airline.

According to the above literatures, we are able to conclude a theoretical framework for the evolution of the ATN of airline, which can provide theoretical basis for the following research, as shown in Figure 1. From the framework, airline market behaviors will prompt the evolution of ATNs, meanwhile the physical characteristics reflected in the evolution of ATNs will support the airlines to implement corresponding strategies to build a network with higher efficiency and sustainability. Moreover, there are many factors influencing the interaction between ATN evolution and airline market behaviors which can be roughly attributed to internal and external dimensions.

Thus, in this paper, we will compare the evolution process of ATNs from three aspects (spatial pattern, topological feature and central city), and analyze the causes of evolutionary differences combining with airline market behaviors, which can provide important inspiration for government to develops airlines. The airline market behaviors mainly include: selecting navigable cities and air routes (i.e. target market regions), designing the type of air routes (i.e. direct and one-stop routes), and establishing airline bases, branch or overnight airports.

\section{Data}

All the data of scheduled domestic routes and flights of the summer flight plans in 2010 and 2016 for the three airlines were extracted from the Official Airline Guide (https://www.oag.cn).

In the network, cities with any airports are 'nodes' and inter-city links with any flight connections form the 'edges'. As a result, the ATN is defined as an undirected network $G=(V, E)$. The set of nodes is defined as $V=$ $\left\{v_{i}: \mathrm{i}=1,2, \ldots n\right\}$, where $v$ is the number of nodes (cities); and the set of edges is defined as $E=\left\{e_{i}: i=\right.$ $1,2, \ldots m\}$, where $e$ is the number of edges (air routes). The data is processed as follows: (i) an adjacency matrix $\mathrm{A}$ is defined such that its element $a_{i j}=1$ when a flight exists between city $i$ and $j$, and $a_{i j}=0$ otherwise; (ii) two or more airports in one city are considered as one node, and related data is merged; (iii) one-stop air route (e.g., a flight A-B-C includes two edges $\mathrm{A}-\mathrm{B}$ and $\mathrm{B}-\mathrm{C}$ ) is decomposed into two-route segments; (iv) the study area is limited to mainland China excluding Hong Kong, Macao, and Taiwan.

\section{Method}

\subsection{Static geometric indexes}

The three types of evaluation index (alpha, beta and gamma) are used to evaluate the complexity and connectivity of the ATN. The formulations of the indexes are as follows:

$$
\begin{aligned}
& \alpha=2(m-n+1) /(n-1)(n-2) \\
& \beta=m / n \\
& \gamma=2 m / n(n-1)
\end{aligned}
$$

where $m$ is the number of edges (air routes); $n$ is the number of nodes (navigable cities); $\alpha$ is the ratio of actual to maximal number of circuits in a fully connected network; $\beta$ is the average number of edges $(m)$ per node $(n) ; \gamma$ is the ratio of actual to maximal number of edges.

Meanwhile, there are three indexes (maximum topological distance, average path length and clustering coefficient) that can be used to measure the reachable efficiency between nodes in ATN (Black, 2003): 


$$
\begin{aligned}
& D=\max _{i, j} d_{i j} \\
& L=2 \sum_{i=1}^{n} \sum_{j=i+1}^{n} d_{i j} / n(n-1) \\
& C=\sum_{i=1}^{n} C_{i} / n=\sum_{i=1}^{n} \frac{2 E_{i}}{k_{i}\left(k_{i}-1\right)} / n
\end{aligned}
$$

where $D$ is the topological distance between the two most remote nodes of a network, denoting the topological distance (i.e., number of edges by the shortest path) from node $i$ to $j$ as $d_{i j}$; $L$ is the average number of edges along the shortest paths for all possible node-pairs in the network; $C$ is the average of all individual $C_{i}$ 's in the network, and the clustering coefficient $\left(C_{i}\right)$ of a node $\mathrm{i}$ is the portion of actual edges $\left(E_{i}\right)$ between the nodes $\left(k_{i}\right)$ within its neighborhood (i.e., all its adjacent nodes excluding the node itself) divided by the maximum number of possible edges between them; $k_{i}$ is the degree of node $i$.

\subsection{Nodal centrality indexes}

Centrality is often used to analyze the relative importance of a node within a network. The degree centrality $\left(D C_{i}\right)$ is a ratio of actual connecting nodes for node $i$ (i.e. $k_{i}$, the degree of node $i$ ) to maximal number nodes. The closeness centrality $\left(C C_{i}\right)$ is the inverse of the average shortest path from a node to all other nodes in a given network, the larger the closeness centrality of node $i$, the more convenient it is to reach other modes. The betweenness centrality $\left(B C_{i}\right)$ measures how often a node is traversed by the shortest paths connecting all pairs of nodes, that is, a node tends to be more powerful if it is on the shortest paths connecting many node-pairs, as it may be in a position to broker or mediate connections between these pairs. The three indexes are as follows:

$$
\begin{aligned}
& D C_{i}=\mathrm{k}_{\mathrm{i}} /(\mathrm{n}-1) \\
& C C_{i}=(n-1) / \sum_{j=1, j \neq i}^{n} d_{i j} \\
& B C_{i}=\left(2 \sum_{k=1}^{n} \sum_{j \neq k}^{n} \frac{\delta_{k j}^{i}}{\delta_{k j}}\right) /(n-1)(n-2)
\end{aligned}
$$

where, $\delta_{i j}^{k}$ is the number of shortest paths between nodes $i$ and $j$ that pass the vertex; and $\delta_{i j}$ is the total number of shortest paths between them.

\section{Result and Analysis}

Comprehensively using statistical analysis and complex network analysis, the three airlines' ATNs were examine spatially and temporally to analyze the differences and causes of three ATNs evolution under different business models.

\subsection{Spatial pattern}

The civil airport is an important transport infrastructure for the exchanges of passengers with the outside. According to the China's Twelfth Five-Year Plan, the CAAC identified five major airport groups: North Airport Group (NAG), East China Airport Group (ECAG), Central Southern Airport Group (CSAG), Southwest Airport Group (SWAG), and Northwest Airport Group (NWAG).

We firstly statistics the spatial and temporal distribution of navigable airports chosen by three airlines in order to preliminary understand the changes of business area for air transport. The number of navigable airports (NA) and navigation rates (i.e. NR, the number of navigable airports in an airport group to the total number of airports in the airport group for an airline) of three airlines in 2010 and 2016 are shown in Figure 2.

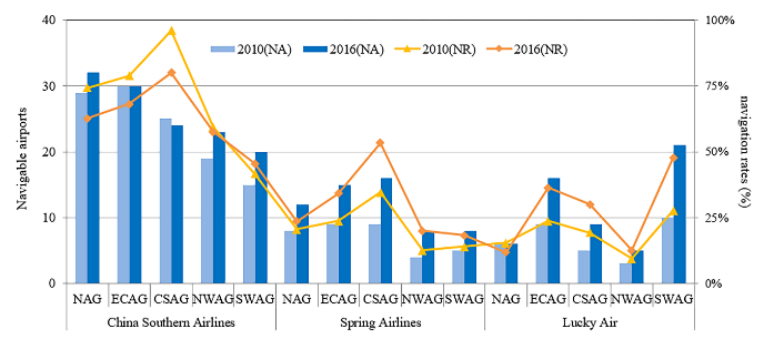

Fig2. The number of navigable airports (NA) and navigation rates (NR) in five airport groups.

The number of navigable airports of China Southern Airlines increased from 118 in 2010 to 129 in 2016. In the case of a decline in the navigation rate of other airport groups, the navigation rate of Southwest Airport Group increased, which suggesting that in this period China Southern Airlines devoted to expand the network to western China where the network has not been substantially covered. For Spring Airlines, the number of navigable airports increased from 35 to 59 and the navigation rates of all five airport groups increased. It also found that although both of the principal bases (Shanghai Hongqiao International Airport and Shanghai Pudong International Airport) of Spring Airlines are located in the East China Airport Group, the East China Region is not the group with the most navigable airports and the Central Southern Airport Group is the group with the most navigable airports. This may have been influenced by the development of high-speed rail in East China. For Lucky Air, the number of navigable airports increased from 33 to 57. The Southwest Airport Group had the largest number of navigable airports and showed the greatest growth, while the number of navigable airports in North Airport Group slightly declined. With the number of navigable airports of three airlines increased, expansion direction for each airline are very different.

For the perspective of distribution of flights, we further analyzed the evolution of spatial pattern of three ATNs. The spatial distribution of round-trip flights per day of navigable cities and air routes are shown in Figure 3 (the color dots in the figure corresponds to the average roundtrip flights per day for the navigable city) and Figure 4 (the thickness and color of the line in the figure correspond to the average round-trip flights per day for the air route). 

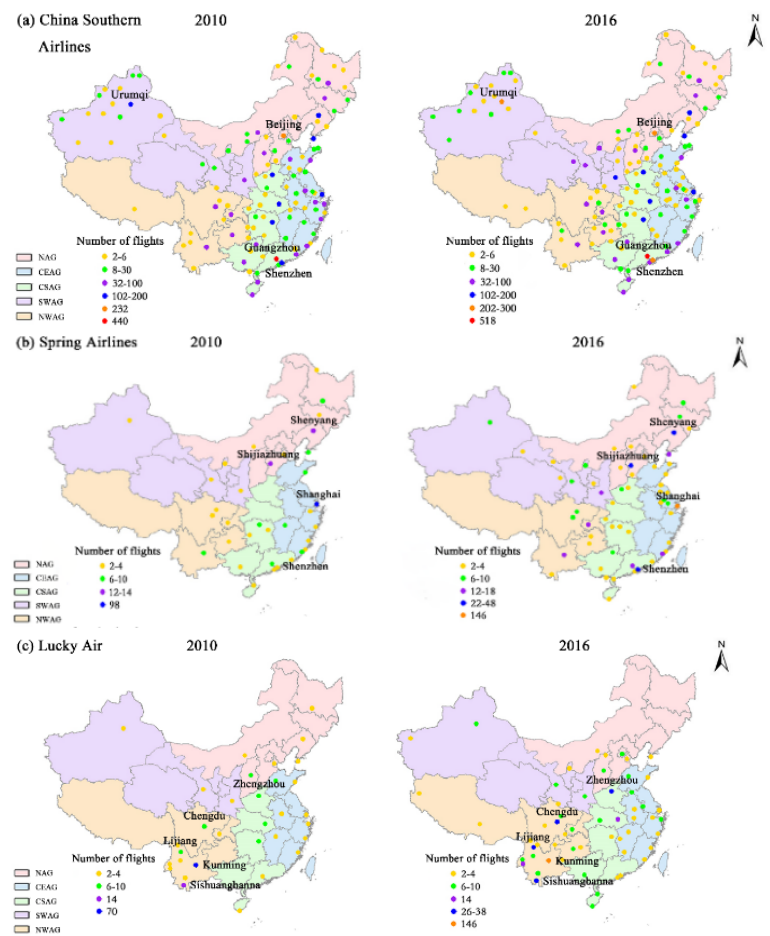

Fig3. Spatial distribution of round-trip flights per day of navigable cities: (a) China Southern Airlines (b) Spring Airlines (c) Lucky Air.

For China Southern Airlines (Figure 3a and Figure 4a), the flights increased significantly in Guangzhou, Urumqi and Shenzhen, and the flights on the air routes from Central Southern Airport Group to Northwest Airport Group, and from Urumqi to other cities also increased. Among these, Guangzhou and Shenzhen are critical for the 'Maritime Silk Road', and Urumqi is not only the base for the China Southern Airlines Xinjiang Branch, but also an important gateway for the westward opening of China's 'One Belt One Road' initiative. These results indicate that the changes in the China Southern Airlines ATN were closely related to the 'One Belt One Road' strategy implemented by the Chinese government in 2013, meaning that China Southern Airlines as a state-owned enterprise directly affiliated with the CAAC will positively respond to the implementation of national policies, which affects the adjustment of ATN.

For Spring Airlines (Figure 3b and Figure 4b), in 2010, the flights were mainly concentrated in Shanghai which is the center of the ATN and the air routes extending from Shanghai. In 2014, in order to expand its low-cost air transport business to other regions, Spring Airlines implemented a domestic network layout strategy which selected Shanghai (East China) as the core and Shenzhen (South China), Shenyang (Northeast China), and Shijiazhuang (North China) as the strategic support points. This led to a rapid increase in the number of flights in these cities, as well as an increase in flights on the regional air routes extending from Shijiazhuang as the second center of ATN.

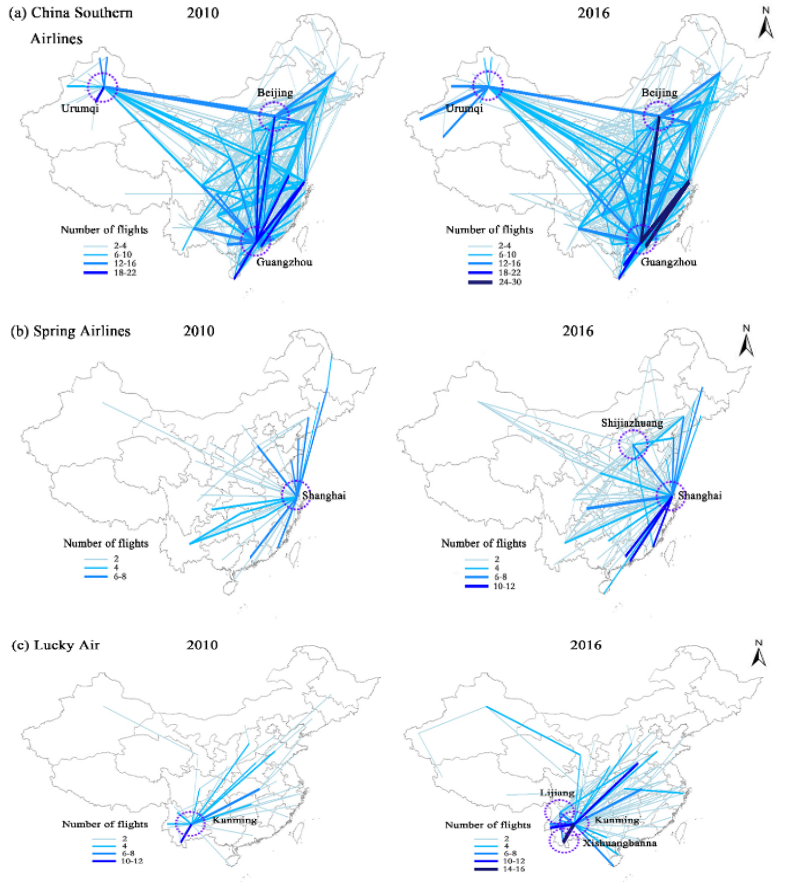

Fig4. Spatial distribution of round-trip flights per day of air routes: (a) China Southern Airlines (b) Spring Airlines (c) Lucky Air.

For Lucky Air (Figure 3c), the largest increase in flights was Kunming, followed by Lijiang, Chengdu, Zhengzhou and Xishuangbanna. With the exception of Zhengzhou and Chengdu, all of these cities are located in the Yunnan Province, on account of the network operation mode for Lucky Air is to achieve dual-directional transport within and outside the province, and to meet the feeder air transportation needs of the province. As shown in Figure $4 \mathrm{c}$, the number of flights in the air routes radiating outward from Kunming, Lijiang, and Xishuangbanna (located in the east, north, and south of Yunnan Province, respectively) increased during 20102016. We can find that Lucky Air ATN is different from China Southern Airlines ATN and Spring Airlines ATN.

The aforementioned suggest that the spatial evolution of three ATNs has the following characteristics and difference:

Based on the distribution of navigable airports, the ATN of China Southern Airlines has the central southern China, northern China and Xinjiang area as the core regions, and the network is expanding from east and central China to the west of China under the guidance of national policies. The ATN distribution of Spring Airlines did not change significantly and mainly concentrated within the East China Airport Group and the North Airport Group, the relationship between the two airport groups became closer with the increase in the number of flights. For the ATN of Lucky Air, whether navigable airports or navigable routes were increasingly concentrated within the Southwest Airport Group.

Based on the distribution of flights, China Southern Airlines have covered different market regions and had been expanding, whereas the target markets of Lucky Air were clearly concentrated within Yunnan Province and other surrounding provinces. The reason for this phenomenon is that Lucky Air as a regional airline can be 
supported by Yunnan State-owned Assets Supervision and Administration Commission, and Yunnan province is located in western China where the ground transportation system is underdeveloped restricted by terrain which is beneficial to develop air transport. Thus, the construction of ATN is mainly conducted in Yunnan Province where Lucky Air has sufficient resources and appropriate condition for air transportation. As a large state-own FSNC, China Southern Airlines has capacity to expand more markets that would yield profit or meet national development needs. As a private LCC, Spring Airlines has more flexible and diverse choice in choosing target markets, thus the market area of Spring Airlines was between the former two.

It could be concluded that the three airlines have made different choices in terms of navigable cities, navigable air routes and target market regions as the result of the different founded background and market positioning of airlines, contributing to the three ATNs expanded across different geographic patterns.

\subsection{Topological feature}

According to the static geometric indexes, the topological features of three ATNs are shown in Table 1, so that we can analyze the evolution of three ATNs for complexity, connectivity and reachable efficiency taking types of routes designed by airlines into account.

Primarily, the alpha index is used to reflect the circling level, showing the complexity of the network. We can find that the alpha index for the ATN of China Southern Airlines decreased from 2010 to 2016, the reason could be that China Southern Airlines mainly launched one-stop air routes and connecting flights during this period was result in the complexity of the ATN is slightly reduced. For Spring Airline and Lucky Air, the alpha indexes of their ATNs have been greatly improved, it suggests that two ATNs had been changed from the star structure centered on a single city to a more complex and better-connected network owing to the increase in direct routes.

Furthermore, from the perspective of network connectivity, the beta index of three ATNs had increased, and the gamma index showed a downward trend, indicating that the overall tightness of three ATNs was weakening. In other word, the newly added nodes are not connected to all the existing nodes in network, but only establishes contact with individual nodes, which will strengthen the centrality of corresponding nodes to a certain extent (in next section will be further analyzed).

Meanwhile, the China Southern Airlines ATN evolved toward a smaller average path length and a larger clustering coefficient, thus resembling a small-world network that most nodes are not neighbors of one another, but most of them can be reached by a small number of edges. By contrast, Lucky Air ATN had the largest average path length and the smallest clustering coefficient in both 2010 and 2016 among the three airlines' ATNs.

It is worth noting that China Southern Airlines ATN had decreased in the indexes of diameter and average path length, while Spring Airlines ATN and Lucky Air ATN increased in the same indexes which shows the development of Spring Airlines ATN and Lucky Air ATN have made more cities reachable need more indirect flights. Thus, the transportation efficiency of later the two is lower than the former. It appears that Spring Airlines and Lucky Air had not taken into consideration of the transportation efficiency in the ATN expansion.

The development level of airline and the type of air route in a certain period will affect the complexity and connectivity of ATN, resulting in different evolution of topological feature for an ATN.

Table1. Topological Features of Three ATNs in 2010 and 2016

\begin{tabular}{|c|c|c|c|c|c|}
\hline Airline & Year & $\begin{array}{l}\text { Node } \\
\text { (n) }\end{array}$ & $\begin{array}{c}\text { Edge } \\
\text { (m) }\end{array}$ & $\underset{(\alpha)}{\text { Alpha }}$ & $\begin{array}{c}\text { Beta } \\
(\beta)\end{array}$ \\
\hline \multirow{2}{*}{$\begin{array}{l}\text { China } \\
\text { Southern } \\
\text { Airlines }\end{array}$} & 2010 & 117 & 465 & 0.0523 & 3.9744 \\
\hline & 2016 & 128 & 515 & 0.0485 & 4.0234 \\
\hline \multirow{2}{*}{$\begin{array}{c}\text { Spring } \\
\text { Airlines }\end{array}$} & 2010 & 34 & 38 & 0.0095 & 1.1176 \\
\hline & 2016 & 57 & 99 & 0.0279 & 1.7368 \\
\hline \multirow{2}{*}{$\begin{array}{l}\text { Lucky } \\
\text { Air }\end{array}$} & 2010 & 32 & 34 & 0.0065 & 1.0625 \\
\hline & 2016 & 56 & 88 & 0.0222 & 1.5714 \\
\hline Airline & Year & $\begin{array}{c}\text { Gamma } \\
(\gamma)\end{array}$ & $\begin{array}{l}\text { Diameter } \\
\text { (D) }\end{array}$ & $\begin{array}{c}\text { Average } \\
\text { path } \\
\text { length } \\
\text { (L) } \\
\end{array}$ & $\begin{array}{l}\text { Clustering } \\
\text { coefficient } \\
\text { (C) }\end{array}$ \\
\hline \multirow{2}{*}{$\begin{array}{l}\text { China } \\
\text { Southern } \\
\text { Airlines }\end{array}$} & 2010 & 0.0685 & 5 & 2.4253 & 0.3424 \\
\hline & 2016 & 0.0634 & 4 & 2.3375 & 0.3639 \\
\hline \multirow{2}{*}{$\begin{array}{c}\text { Spring } \\
\text { Airlines }\end{array}$} & 2010 & 0.0677 & 4 & 2.1408 & 0.0786 \\
\hline & 2016 & 0.062 & 5 & 2.3133 & 0.3162 \\
\hline \multirow{2}{*}{$\begin{array}{l}\text { Lucky } \\
\text { Air }\end{array}$} & 2010 & 0.0685 & 4 & 2.4516 & 0.0786 \\
\hline & 2016 & 0.0571 & 5 & 2.5247 & 0.3081 \\
\hline
\end{tabular}

\subsection{Central city}

Three nodal centrality indexes: degree centrality, closeness centrality and betweenness centrality are introduced to capture a city's importance in terms of being directly connected to others (i.e. direct accessibility), being accessible to others (i.e. indirect accessibility), and being the intermediary (i.e. transfer function) between other cities. Based on the changes of the nodal centrality, further explore the reasons for the transformation of city function under different market behaviors. The calculation results are illustrated as shown in Figure 5-7 (the size of the circle in the figure is proportional to the value of nodal centrality).

Figure 5 shows the change in nodal centrality for the ATN of China Southern Airlines. It could be seen that although Guangzhou's centrality increased and the centrality of Shanghai, Beijing, Urumqi and Kunming decreased, the basic configuration of the central city did not change from 2010 to 2016. In 2012, China Southern Airlines established the Henan Branch in Zhengzhou that is a key city in the northern line of the Silk Road Economic Belt, then we can find that the centrality of Zhengzhou significantly increased. While the accessibility of Shenzhen weakened, the intermediary improved, because China Southern Airlines implemented a differentiation strategy for the two cities in the same 
region, which planning to Shenzhen as a regional hub and creating Guangzhou become a domestic and international composite hub. Overall, China Southern Airlines has established regional central cities for its network.

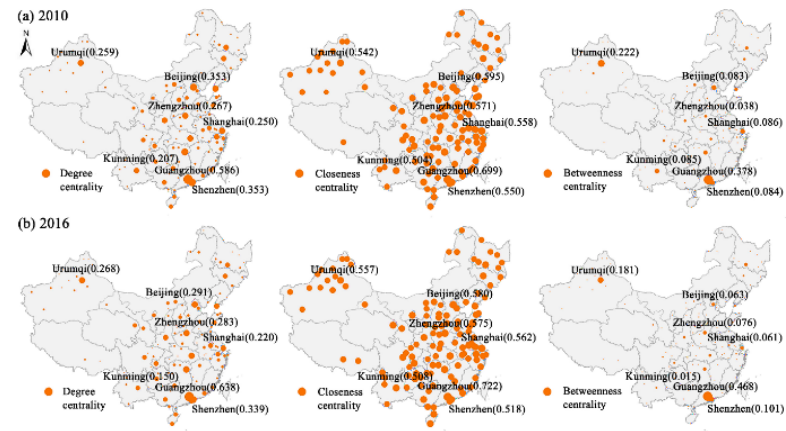

Fig5. Spatial distribution of node centrality for China Southern Airlines ATN

Figure 6 shows that with the scale of Spring Airlines was largely expanded, the airline set Shijiazhuang and Shenyang as second operating bases as a result that the centrality of Shijiazhuang and Shenyang strengthened, meanwhile the centrality of Shanghai weakened. The accessibility and transfer function of Shenzhen and Yangzhou were also enhanced significantly, because Spring Airlines in 2014 and 2016 respectively set up overnight airports for aircraft in Shenzhen and Yangzhou, Yangzhou is also the third base for Spring Airlines. Besides, the centrality of Urumqi and Kunming slightly increased, which suggests Spring Airlines tends to establish bases in western China. These results indicate that the structure of ATN of Spring Airlines has a tendency to evolve into multiple central cities.

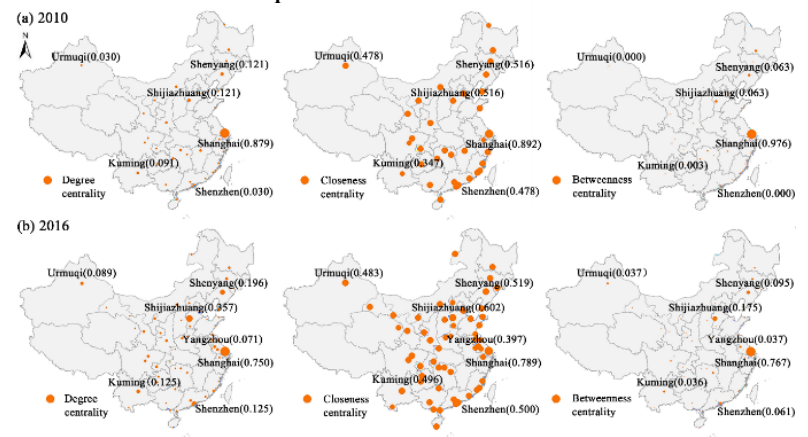

Fig6. Spatial distribution of node centrality for Spring Airlines ATN

Figure 7 shows that the centrality of Kunming in the Lucky Air ATN was the strongest, and the centrality of Chengdu replaced Wuhan as the second strongest in 2016. The reason for this phenomenon is that Lucky Air established the Chengdu branch in 2014, then increased the direct flights from Chengdu to Yunnan Province and other routes from Chengdu to cities across China, which makes Chengdu become a central city. Moreover, the accessibility of Lijiang and Zhengzhou increased, as well as the intermediary of Urumqi. Among these, Lijiang and Zhengzhou are bases respectively established in 2013 and 2016 for Lucky Air. It could be seen that Kunming, Chengdu and Lijiang mentioned above are all located in the Southwest Airport Group, showing the distribution of central cities for the ATN of Lucky Air was concentrated mainly within one region.
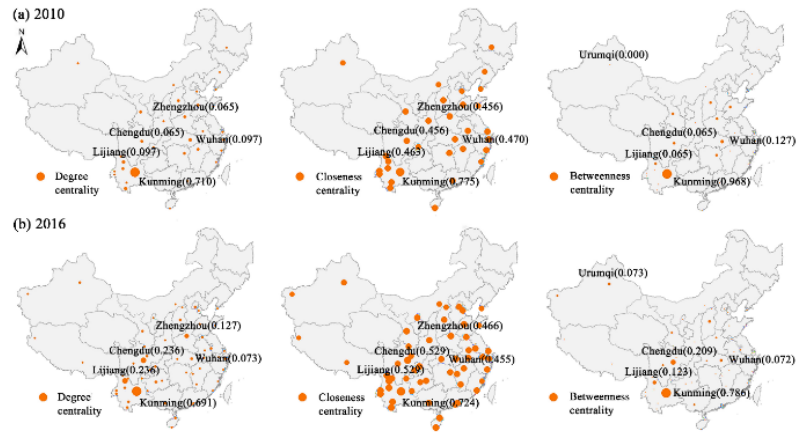

Fig7. Spatial distribution of node centrality for Lucky Air ATN

Compared cities with high centrality in three ATNs, we can find that Spring Airlines primarily chose the provincial capitals to develop bases instead of cities that the comprehensive strength in the most advanced level in mainland China. For example, Spring Airlines established base in Shijiazhuang which is in the same region as Beijing and it only takes 1.5 hours from Shijiazhuang to Beijing by high-speed rail. Spring Airlines not only avoid competing with other airlines for flights in Beijing Capital International Airport, it can also effectively reduce costs and further its development with local government incentives.

The above evolution characteristics show that airlines with different business models have differences in establishing bases, branches and overnight airports, which reflects in the changes in nodal centrality.

\section{Conclusion}

On the basis of comparing the evolution of three ATNs for China Southern Airlines, Spring Airlines and Lucky Air, the paper shows the evolution differences and causes of three ATNs under the influence of airline market behaviors:

- As a state-own FSNC, China southern airlines is easily affected by national policy that has marketoriented effect, and adopted corresponding strategies making the expansion of the ATN. As a private LCC, Spring Airlines has more flexible choice in choosing target markets, and the ATN had a transformation from a mono-centric (Shanghai) divergence network to a two-centric regional (eastern and northern China) one during 2010-2016. Lucky Air, as a regional feeder carrier and young local enterprise in Yunnan Province, whether airports or routes increasingly concentrated within the southwest of China.

- At the advanced development stage, China Southern Airlines with large business scale aims to form a hub-and-spoke system and launched one-stop air routes which is beneficial to improve the interoperability between cities, besides the ATN evolves to a small-world network. However, Spring Airlines and Lucky Air are still in the initial stage of development, the increasing number of point-to-point air routes makes average path length of ATNs increased, which deduces the transport efficiency of the whole ATNs.

- China Southern Airlines has established several bases and branches that cover all airport groups in 
China, thus the distribution of central cities is widespread compared with Spring Airlines and Lucky Air. Spring Airlines tends to choose provincial capitals with weak economic strength to develop bases instead of metropolis, and the ATN has a tendency to evolve into multiple central cities. For Lucky Air, the expansion of central cities is still around Yunnan Province.

The reason for the differential evolution of three ATNs can be attributed to the enterprises themselves (e.g., founded background, market positioning, stage of development) and airline market operation strategies with the effects of external environment (e.g., national policy, market condition).

From the evolutionary characteristics of the ATNs under different airline business models, full-service network carriers are conducive to develop international air routes to transport passengers to foreign countries by virtue of the developed ATN. Low-cost carriers have an advantage in providing specific air transport services, such as 'air-rail integration'. Regional feeder carriers are suitable for providing air transport services to areas where ground transportation is underdeveloped, such as western China. This information obtained is important from government perspective to improve and consolidate the structure of the national ATN by developing targeted airlines. On the other hand, airlines can identify the development trend of ATNs of their competitors and adopt appropriate operation strategies to adjust the own ATN for sustainability evolution.

However, there are still some limitations to the study. The market is decisive in a liberalized airline system, and hence also the impact of airline alliances as well as competitive responses of main competitors (other airline with conflicts of interest, high-speed rail) would need to be studied in the future.

\section{Acknowledgment}

This work was supported by National Natural Science Foundation of China (U1933118), and National Key Research and Development Project under Grant (2018YFB1601200).

\section{References}

1. Wang, J.; Bonilla, D.; Banister, D. Air deregulation in China and its impact on airline competition 19942012. J. Transp. Geogr. 2016, 50, 12-23. DOI: 10.1016/j.jtrangeo.2015.03.007.

2. Teece, D. J. Business models, business strategy and innovation. Long Range Plan 2010, 43, 172-194. DOI: 10.1016/j.lrp.2009.07.003.

3. Nekovee, M.; Moreno, Y.; Bianconi, G.; Marsili, M. Theory of rumour spreading in complex social networks. Phys. A Stat. Mech. Appl. 2006, 374, 457470. DOI: 10.1016/j.physa.2006.07.017.

4. Guimerà, R.; Amaral, L.A.N. Modeling the worldwide airport network. Eur. Phys. J. B 2004, 38, 381385. DOI: $10.1140 /$ epjb/e2004-00131-0.
5. Hsu, C.; Shih, H. Small-world network theory in the study of network connectivity and efficiency of complementary international airline alliances. J. Air Transp. Manag. 2008, 14, 123-129. DOI: 10.1016/j.jairtraman.2008.02.007.

6. Cardillo, A.; Gómez-Gardees, J.; Zanin, M.; Romance, M.; Papo, D.; Pozo, F.D.; Boccaletti, S. Emergence of network features from multiplexity. Sci. Rep 2013, 3, 1344-1352. DOI: $10.1038 /$ srep01344.

7. Lordan, O.; Sallan, J.M. Analyzing the multilevel structure of the European airport network. Chin. J. Aeronaut 2017, 30, 554-560. DOI: 10.1016/j.cja.2017.01.013.

8. Bagler, G. Analysis of the airport network of India as a complex weighted network. Phys. A Stat. Mech. Appl. 2008, 387, 2972-2980. DOI: 10.1016/j.physa.2008.01.077.

9. Guida, M.; Maria, F. Topology of the Italian airport network: A scale-free small-world network with a fractal structure? Chaos Solitons Fractals 2007, 31, 527-536. DOI: 10.1016/j.chaos.2006.02.007.

10. Xu, Z.; Harriss, R. Exploring the structure of the US intercity passenger air transportation network: a weighted complex network approach. Geojournal 2008, 73, 87-102. DOI: 10.2307/41148284.

11. Wang, J.; Mo, H.; Wang, F.; Jin, F. Exploring the network structure and nodal centrality of China's air transport network: A complex network approach. J. Transp. Geogr. 2011, 19, 712-721. DOI: 10.1016/j.jtrangeo.2010.08.012.

12. Cui, B.; Pan, S. Core-Peripheral model of Chinese civil aviation network. J. Tran. Sys. Eng. \& Info. Tech. 2014, 14, 14-36. DOI: 10.3969/j.issn.10096744.2014.05.002.

13. Du, W. B.; Zhou, X. L.; Lordan, O.; Wang, Z.; Zhao, C.; Zhu, Y. B. Analysis of the Chinese airline network as multi-layer networks. Transp. Res. Part E 2016, 89, 108-116. DOI: 10.1016/j.tre.2016.03.009.

14. Lin, J.; Ban, Y. The evolving network structure of us airline system during 1990-2010. Phys. A Stat. Mech. Appl. 2014, 410, 302-312. DOI: 10.1016/j.physa.2014.05.040.

15. Wang, J.; Mo, H.; Wang, F. Evolution of air transport network of china 1930-2012. J. Transp. Geogr. 2014, 40, 145-158. DOI: 10.1016/j.jtrangeo.2014.02.002.

16. Wong, W. H.; Cheung, T.; Zhang, A. Is spatial dispersal the dominant trend in air transport development? A global analysis for 2006-2015. J. Air Transp. Manag. 2019, 74, 1-12. DOI: 10.1016/j.jairtraman.2018.09.011.

17. Su, M.; Luan, W.; Li, Z.; Wan, S.; Zhang, Z. Evolution and Determinants of an Air Transport Network: A Case Study of the Chinese Main Air Transport Network. Sustainability 2019, 11, 3933. DOI: 10.3390/su11143933.

18. Jiao, J.; Wang, J. Spatial structure and evolution of Hainan Airlines Network: An analysis of complex network. Geogr. Res. 2014, 33, 926-936. DOI: 
10.11821/dlyj201405011.

19. Jiang, Y.; Yao, B.; Wang, L.; Feng, T.; Kong, L. Evolution trends of the network structure of spring airlines in china: A temporal and spatial analysis. J. Air Transp. Manag. 2017, 60, 18-30. DOI: 10.1016/j.jairtraman.2016.12.009.

20. Halpern, N.; Graham, A.; Dennis, N. Low cost carriers and the changing fortunes of airports in the UK. Res. Transp. Bus. Manag. 2016, 21, 33-43. DOI: 10.1016/j.rtbm.2016.05.002.

21. Dobruszkes, F. The geography of European low-cost airline networks: a contemporary analysis. J. Transp. Geogr. 2013, 28, 75-88. DOI: 10.1016/j.jtrangeo.2012.10.012.

22. John, T.; Bowen, J. A spatial analysis of FedEx and UPS: Hubs, spokes, and network structure. J. Transp. Geogr. 2012, 24, 419-431. DOI: 10.1016/j.jtrangeo.2012.04.017. 